\title{
Accueillir l'enfant illégitime : modalités, enjeux, limites de la benignitas canonica
}

Des théories romano-canoniques aux pratiques sociales ( $\mathrm{XII}^{\mathrm{E}}-\mathrm{XV}^{\mathrm{E}}$ SIÈCLES)

Welcoming illegitimate children: modalities, issues and the limitations of the benignitas canonica. From Romano-Canonic theories to social practice

(11th-15th centuries)

\section{Carole Avignon}

\section{(2) OpenEdition}

1 Journals

Édition électronique

URL: http://journals.openedition.org/abpo/3694

DOI : $10.4000 / a b p o .3694$

ISBN : 978-2-7535-6539-5

ISSN : 2108-6443

\section{Éditeur}

Presses universitaires de Rennes

Édition imprimée

Date de publication : 16 novembre 2017

Pagination : $65-86$

ISBN : 978-2-7535-5674-4

ISSN : 0399-0826

\section{Référence électronique}

Carole Avignon, «Accueillir l'enfant illégitime : modalités, enjeux, limites de la benignitas canonica », Annales de Bretagne et des Pays de l'Ouest [En ligne], 124-3 | 2017, mis en ligne le 16 novembre 2019, consulté le 08 janvier 2020. URL : http://journals.openedition.org/abpo/3694 ; DOI : 10.4000/abpo. 3694 


\title{
Accueillir l'enfant illégitime : modalités, enjeux, limites de la benignitas canonica

\author{
Des théories romano-canoniques \\ aux pratiques sociales $\left(\mathrm{XII}^{\mathrm{e}}-\mathrm{XV}^{\mathrm{e}}\right.$ siècles)
}

\begin{abstract}
Carole Avignon
Maître de conférences en histoire du Moyen Âge, CERHIO CNRS, université d'Angers, université Bretagne Loire
\end{abstract}

"Comment la société médiévale accueillait en son sein les enfants et les adolescents ", tel était l'objet de recherche qui réunissait déjà en 1981 les historiens médiévistes assemblés en congrès ${ }^{1}$. Dans ses notes critiques consacrées à l'étude de ces Entrées dans la vie, Jacques Verger saluait le recours au concept médiéval d' "âges de la vie " pour organiser la réflexion des communicants, à côté de ceux de " rites d'initiation " et d' "éducation ",

1. La formule est de Jacques Verger rendant compte des éclairages apportés au colloque par l'introduction de John Benton (p. 9-14) et la conclusion de Michel Rouche (p. 245-251). Les entrées dans la vie. Initiations et apprentissages. XII ${ }^{\mathrm{e}}$ congrès de la Société des Historiens de l'Enseignement Supérieur Public, Nancy, Presses Universitaires de Nancy, 1982; VERGER, Jacques, " Notes critiques ", Histoire de l'éducation, 1983, vol. 18, n 1 , p. 109-112. L'année précédente, en 1980, l'université de Provence consacrait le numéro 9 de sa revue Senefiance à L'enfant au Moyen Âge (littérature et civilisation). Voir Riché, Pierre, ALEXANDRE-Bidon, Danièle, "L'enfant au Moyen Âge : état de la question ", dans Robert Fossier (dir.), La petite enfance dans l'Europe médiévale et moderne, Actes des $\mathrm{XVI}^{\text {es }}$ journées internationales d'histoire de l'Abbaye de Flaran, septembre 1994, Toulouse, Presses universitaires du Mirail, 1997, p. 7-29 ou ALEXANDRE-Bidon, Danièle, LeTt, Didier, Les enfants au Moyen Âge, Paris, Hachette, collection " La vie quotidienne ", Paris, 1997, p. 9-13; LETT, Didier, L'enfant des miracles. Enfance et société au Moyen Âge (XII - -XIII siècles), Paris, Aubier, collection historique, 1997, p. 10-18). La petite enfance devint aussi en 1997 l'objet d'études spécifiques de la part d'anthropologues, démographes, historiens, médecins, et psychologues regroupés au sein d'un GDR coordonné par l'ethnologue Suzanne Lallemand. Voir Lallemand, Suzanne, La circulation des enfants en société traditionnelle. Prêt, don, échanges, Paris, 1993. Pour un bilan historiographique récent : LETT, Didier, RoBIN, Isabelle et RoLLET, Catherine, « Faire l'histoire des enfants au début du Xxle siècle : de l'enfance aux enfants ", 50 ans de démographie historique. Bilan historiographique d'une discipline en renouvellement, Annales de Démographie Historique, 2015-1, n 129, p. 231-276. 
tout en regrettant que n'aient pas été davantage envisagés conjointement les deux premiers (âges de la vie et rites d'initiation); il appelait aussi de ses vœux l'ouverture de nouveaux chantiers de recherche, notamment sur le développement du petit enfant. Les contributeurs du colloque de Flaran en 1997 étaient également invités à s'intéresser à l'enfant médiéval, infans et puer $^{2}$. C'est à ces deux âges de la vie que nous nous intéressons aujourd'hui.

Qu'advient-il quand les enfants ne naissent pas d'un couple de géniteurs légalement mariés aux yeux de cette Église médiévale qui légifère et juge depuis le $\mathrm{XI}^{\mathrm{e}}$ siècle sur les questions relatives à la définition du lien matrimonial? Un folio d'un manuscrit de la Concordia discordantium canonum de Gratien, copié au XIII ${ }^{\mathrm{e}}$ siècle, présente une enluminure mettant en scène une figure d'évêque (assis sur une cathèdre, la mitre l'identifie), séparant un homme (à droite de l'image) et une femme (à gauche). Sa main droite s'élève pour lui signifier de ne plus approcher de l'homme qu'il pointe d'un index réprobateur et dont l'attitude affligée est manifestée par un jeu de mains portées à son visage, incliné ${ }^{3}$. La femme porte sur son bras droit un nourrisson emmailloté qu'elle semble vouloir protéger d'un geste de la main gauche. Les regards des trois adultes sont tournés vers la gauche de l'image, vers ce petit enfant emmailloté. Cette enluminure apparaît parmi les folios de la Cause 30 du Décret de Gratien, celle-là même qui traite, dans la seconde partie de cette compilation raisonnée d'autorités canoniques, de la parenté spirituelle, de l'âge des fiançailles et du mariage, de la fraternité spirituelle, de la parenté spirituelle, ou des mariages clandestins, qui peuvent (à des degrés divers) constituer des empêchements au mariage (les mariages, bien que clandestins, sont valides en droit, mais le défaut de publicité qui les grève peut permettre de dissimuler des empêchements au projet de mariage $)^{4}$. Bien sûr, la bâtardise de cet enfant ne saurait être établie sans un minimum de précautions d'analyse, précisément parce qu'elle est une condition juridique et non un état de nature, parce qu'elle procède de régimes juridiques qu'élabore le droit (conciliaire et pontifical), qu'affine la doctrine (celle des commentateurs du Décret de Gratien, mais aussi et surtout du Liber extra qui compile en 1234, sur ordre de Grégoire IX, les

2. SigAL, Pierre André, " Le vocabulaire de l'enfance et de l'adolescence dans les recueils de miracles latins des $\mathrm{XI}^{\mathrm{e}}$ et XII ${ }^{\mathrm{e}}$ siècles ", L'enfant au Moyen Âge, Senefiance, 1980, $\mathrm{n}^{\circ} 9$, p. 80-85 : il illustre la très grande variation des âges invoqués pour des infantes (bébé au berceau, enfant d'un an, enfant de cinq ans, p. 82), des pueri (sur 44 mentions d'âge pour un puer de la naissance à quinze ans, et presqu'autant de 0 à 6 ans que de 7 à 13 ans, p. 82) ou des puellae (sur 16 mentions, davantage au-delà de 12 ans qu'entre 0 à 12, p. 84). LeTT, Didier, L'enfant des miracles..., op. cit., chap. 1 "Les âges de l'enfance ", p. 18-39; chap. 2 "Le vocabulaire de l'enfance", p. 41-52.

3. Bib. mun. d'Amiens, ms 0353, fo $311 \mathrm{v}^{\mathrm{o}}$. Voir la couverture de Carole Avignon (dir.), Bâtards et bâtardises dans l'Europe médiévale et moderne, Rennes, PUR, 2016.

4. Gratien, Décret de Gratien, causes 27 à 36. Le Mariage, édition, traduction et notes de Jean WerckmeISTER, Paris, Cerf, 2011. Sur la théorie des empêchements au mariage, et leurs incidences (dirimantes ou prohibitives) sur le lien matrimonial, voir en première intention GAUDEMET, Jean, Le mariage en Occident. Les moeurs et le droit, Paris, Cerf, 1987. 
décrétales pontificales du jus novum triomphant depuis la seconde moitié du $\mathrm{XII}^{\mathrm{e}}$ siècle) et que mettent en ouvre les juges des tribunaux ecclésiastiques. La bâtardise est pensée d'abord comme un defectus natalium, un " défaut de naissance " qui permet, depuis le concile de Bourges de 1031, de stigmatiser par des incapacités personnelles les fils de clercs majeurs, puis toute progéniture de laïcs conçue en dehors de ce cadre matrimonial que l'Église leur réserve et leur assigne sous son contrôle ${ }^{5}$. La discrimination juridique de l'enfant illégitime peut toutefois être régularisée par des tempéraments canoniques si ses géniteurs ne l'ont pas conçu dans l'adultère ou l'inceste. Elle peut être également amendée par des dispositifs gracieux (dispense pontificale quoad spiritualia; légitimation par rescrit ou par lettres royaux, quoad temporalia $)^{6}$. Les grands papes de l'articulation des $\mathrm{XII}^{\mathrm{e}}$ et XIII ${ }^{\mathrm{e}}$ siècles conçoivent des dispositifs canoniques qui permettent à des enfants qui auraient dû subir le régime de la bâtardise de ne pas être considérés comme des " illégitimes ${ }^{7}$ ".

Bâtard ou non, le sort de ce premier enfant pose question, comme celui représenté emmailloté dans son berceau qui illustre un folio d'un manuscrit du Tractatus Omne bonum, attribué au cistercien anglais Jacobus Anglicus

5. Sur les questions relatives à la bâtardise, voir l'introduction mais aussi les contributions de la première partie ("Les régimes juridiques de la bâtardise et leurs enjeux disciplinaires et politiques ", notamment celle d'Arnaud FossiER) de Carole Avignon (dir.), Bâtards et bâtardises..., op. cit., p. 11-34 et p. 59-174. Pour une approche synthétique sur la norme matrimoniale, entre autres publications fort nombreuses référencées, AviGNON, Carole, "Cadrage et contrôle du mariage ", dans DE CEVINS, Marie-Madeleine, MATz, JeanMichel (dir.), Structures et dynamiques religieuses dans les sociétés de l'Occident latin (11791449), Rennes, PUR, 2010, p. 511-522.

6. GÉNESTAL, Robert, Histoire de la légitimation des enfants naturels en droit canonique, Paris, 1905. Sur le refus du principe canonique de la décrétale d'Alexandre III Conquestus (Liber Extra [abrégé ensuite X.], IV, 17, 1) dans l'Angleterre médiévale, voir HELMHOLZ, Richard, " Bastardy litigation in Medieval England ", The American Journal of Legal History, 13-4, octobre 1969, p. 360-383. Sur les développements critiques autour de ce principe canonique, voir les articles d'Anne LEFEBVRE-TEILLARD, en grande partie réédités dans Autour de l'enfant. Du droit canonique et romain médiéval au Code civil de 1804, Leyde, Boston, Brill, 2008. Nous les avons succinctement résumés dans "Pour une histoire sociale et culturelle de la bâtardise ", dans Avignon, Carole (dir.), Bâtards et bâtardises..., op. cit., p. 11-34. Sur la décrétale Tanta (X., Iv, 17,6), voir LEFEBVRE-TEILLARD, Anne, "Tanta est vis matrimonii : remarques sur la légitimation par mariage subséquent de l'enfant adultérin ", Autour de l'enfant..., op. cit., p. 287-300. Sur la légitimation par rescrit, voir DELBEz, Louis, De la légitimation par "Lettres royaux ». Étude d'ancien droit français, Montpellier, impr. de l'Économiste méridional, 1923, et les développements dans Carole Avignon (dir.), Bâtards et bâtardises..., op. cit., notamment les contributions de Marta PEguERA-PocH et de Carole Avignon.

7. Sur la rétroaction, et ses enjeux en droit, voir notamment LEFEBVRE-TEILLARD, Anne, chapitres XXI et XXIII, Autour de l'enfant..., op. cit., p. 329-342 et p. 359-373; sur le mariage putatif, voir Cum inter, $X$., IV , 17, 2 (Alexandre III : " les enfants sont tenus néanmoins pour légitimes ", non minus habeantur legitimi, s'ils sont nés avant le prononcé de la " sentence canonique de divorce " (comprenons d'annulation du mariage célébré publiquement, publice, par les parents) et Ex tenore, X., IV, 17, 14 (Innocent III, qui introduit l'expression " in favorem prolis"). 
mort avant $1352^{8}$. Est-il le fruit des amours sacrilèges d'un moine et de sa concubine? Il est celui qu'on montre du doigt et qui est seul : ce sont là, figurés visuellement, les stigmates du bâtard et de sa condition première de "sans famille", sans gens ni genus ${ }^{9}$. Les enluminures en marge de la Legenda aurea de Jacques de Voragine étudiées par Chloé Maillet ne fonctionnent pas selon les mêmes schémas discursifs que ces deux premiers exemples, mais elles mettent aussi en scène des enfants illégitimes pour qui se pose la question de l'accueil ${ }^{10}$. L'un des schémas iconographiques qu'elle propose repose sur l'exemple de saint(e) Marin(e). Le petit enfant emmailloté semble blotti sur les genoux de Marin(e), vierge travestie en moine, qui le regarde et peut-être lui parle, dans une attitude bienveillante qui rappelle la gestuelle du personnage féminin de l'enluminure de Gratien. Est-ce ce qui trahirait le genre de ce moine pour l'enlumineur qui connaît le ressort de la transgression, - non pas la paternité illicite (et impossible puisque le prétendu père est une femme), mais le travestissement? On notera après Chloé Maillet la liberté prise par l'enlumineur par rapport au texte qui spécifiait que "l'enfant ne lui avait été confié qu'après trois ans, une fois sevré ${ }^{11}$ ". La figuration de rejet d'Agar et d'Ismaël né d'Abraham et de cette concubine esclave au temps de la stérilité de Sara, brouille aussi parfois les références d'âge. L'enfant n'est plus censé en être un, puisqu'il a sans doute 14 ans, mais l'iconographie des bibles historiales le figure en puer aux vêtements courts, et parfois même en infans emmailloté ${ }^{12}$. Priorité n'est pas au réalisme, mais à la convocation de signifiants. Ainsi, après que l'homme (Abraham) a chassé son fils, c'est Dieu indirectement qui le " recueille " en indiquant à Agar comment lui donner à boire et ainsi le maintenir en vie (Gn., 16, 1-15). La signification de cet accueil et de ce soin minimal et salvateur est double : elle permet de rappeler ici que, même

8. Jacobus Anglicus, Omne bonum, Londres, British Library, ms Royal $6^{\mathrm{E}} \mathrm{VI}$, fo 296 vo. Voir couverture de GAuvard, Claude, Stella, Alessandro (dir.), Couples en justice, $I^{e}$-XIXe siècle, Paris, Publications de la Sorbonne, 2013.

9. Ce topos du bâtard sans famille (puisqu'exclu du périmètre juridique de la famille, celle dont on hérite, justement) est bien sûr à historiciser et contextualiser selon les sources normatives qu'on aborde : nous en avons discuté dans Avignon, Carole, "Sans gens ni genus? Configurations coutumières, reconfigurations pratiques de la condition de l'enfant illégitime (XII ${ }^{\mathrm{e}}-\mathrm{XV}^{\mathrm{e}}$ siècles) ", dans eadem, Bâtards et bâtardises..., op. cit., p. 135146. Voir aussi pour la période moderne, et l'impression dominante de « demande sociale contradictoire " comme de " réponses de l'administration et de la justice " en la matière, StEINBERG, Sylvie, Une tache au front. La bâtardise aux XVT et XVII siècles, Paris, Albin Michel, 2016, spécialement chapitre 4 "Sans famille? ", p. 189-237.

10. MAILLET, Chloé, « La filiation spirituelle face à l'illégitimité. Accusation de paternité et transgenres altimédiévaux de la Légende dorée (XIII siècle) ", dans Avignon, Carole, Bâtards et bâtardises..., op. cit., p. 393-404.

11. MallLet, Chloé, "La filiation spirituelle face à l'illégitimité... ", art. cité, p. 402 . BnF, ms. esp. 44, fo $123 \mathrm{v}^{\mathrm{o}}$, Legenda aurea.

12. En puer, voir notamment : BnF, ms. 50, fo $44 \mathrm{v}^{\mathrm{o}}$; ms. 15397, fo $33 \mathrm{v}^{\mathrm{o}}$ (Agar est alors présentée chassée avec un simple baluchon à l'épaule; l'image suivante illustre toutefois comment l'archange lui indique la présence d'un puits pour qu'elle puisse donner à boire à l'enfant trop affaibli pour tenir debout). En nourrisson emmailloté : BnF, ms. 160, fo $20 \mathrm{v}^{\circ}$. 
conçu et né dans le péché par ses géniteurs, l'enfant illégitime est accueilli dans l'ecclesia par le baptême et que l'enfant doit être " nourri ".

Dans ces différentes représentions iconographiques, s'impose un hiatus entre couple parental et couple conjugal. Comment les enfants sont-ils pris en charge et sous le toit de qui? Comment fonctionne la parentalité quand la conjugalité est impossible ou récusée (par une des parties ou un juge)? En questionnant les discours canoniques, puis en recherchant dans les archives de la pratique la trace des situations vécues par les médiévaux, nous nous proposons de saisir quelques-unes des logiques qui président, en théorie comme en pratique, à la prise en charge des enfants illégitimes. Nous nous proposons de retisser le fil du discours canonique sur les contours de l'obligation qu'il y a à "alere filium ", en mettant finalement en regard ces pratiques (autorisées, au sens propre par le discours juridique romain, puisque le jurisconsulte Paul disait déjà dans le Digeste [25, 3, 4] que ne pas nourrir un enfant équivaut à le tuer), avec les recherches d'historiens sur la parenté vécue, et les travaux d'anthropologues de la petite enfance. Nous souhaitons ainsi poser les jalons d'une réflexion sur ce que ces circulations particulières d'enfants qu'on " donne " parce qu'il faut les « nourrir " nous disent dans les représentations médiévales de l'articulation entre la nature et le droit, la caritas et la favor prolis.

\section{Définir en droit la filiation : genera (" extractions "), droits et devoirs}

L'étude de la filiation constitue l'un des biais pour appréhender ce qu'il en est du statut de l'enfant en droit canonique. Les difficultés d'appréhension de ce statut ont été exposées en 1976 dans un article de René Metz qui rappelait la grande dispersion des éléments de réflexion consacrés à l'enfant comme la dette de la pensée canonique à l'égard des autorités du droit romain ${ }^{13}$. La nécessaire articulation entre droit romain et droit canon se vérifie encore dans le dossier qui nous occupe, la question de l'entretien de l'enfant illégitime en marge de la définition des enjeux de l'établissement d'une filiation légitime.

Le titre 17 du livre IV du Liber extra permet de définir les contours de la filiation légitime et de préciser les conséquences juridiques de la reconnaissance de la filiation et de la légitimité de celle-ci. Dans le droit canon tel qu'il s'élabore et s'affine à partir de la seconde moitié du XII ${ }^{\mathrm{e}}$ siècle, la légitimité relève d'une opération juridique complexe qui est fonction d'une

13. METz, René, "L'enfant dans le droit canonique médiéval. Orientations de recherche ", Recueil de la Société Jean Bodin, 36, 1976, p. 9-96, réimprimé dans La femme et l'enfant dans le droit canonique médiéval, Londres, Variorum Reprints, 1985, spécialement p. 9 et 16. L'historien du droit s'était appuyé sur des sondages dans les grandes compilations du jus antiquum (Gratien) et du jus novum (le Liber extra) commentées par Jean le Teutonique puis Barthelémy de Brescia, pour le premier, Bernard de Parme, Hostiensis (Lectura et Summa) et Jean d'André pour le second (voir p. 16). Nous avons limité notre approche au seul jus novum, même si les décrétalistes consultés ont ponctuellement renvoyé à des distinctions du Décret de Gratien. 
combinaison de critères nécessairement articulés à la situation matrimoniale des géniteurs, par ailleurs soumise à des temporalités multiples : on naît légitime, mais on peut aussi le devenir (X. IV, 17, c. 1 [Conquestus], c. 6 [Tanta est vis matrimonii $]^{14}$. On peut aussi le rester en dépit de l'annulation du mariage des géniteurs qui auraient négligé de bonne foi un empêchement dirimant à leur projet d'union célébrée publiquement in facie ecclesie (X. IV, 17, c. 2, Cum inter). Seul le spurius, né d'un adultère, d'un inceste ou d'un sacrilège, est exclu de ces dispositifs. L'impossibilité dans laquelle se trouvent ses géniteurs de contracter un mariage réparateur même après le décès du conjoint indésirable construit ainsi une ligne de fracture entre celui qui est qualifié de naturalis (et appelé ainsi, dans la glose du XIve siècle proposée par Jean d'André, parce qu'il n'est pas inclus dans la puissance paternelle [naturalis, quod non est in patris potestate]) ${ }^{15}$ et le spurius ${ }^{16}$. C'est par l'exclusion de l'héritage (hereditas) paternel que le droit canonique signifie le rejet du spurius, en faisant de celle-ci le marqueur juridique de l'illégitimité (et ab hereditate repellendus).

La temporalité juridique de la décrétale Tanta est sans appel. La glose ordinaire de repellendus précise les types de filiation possible (les qualités qu'on peut donc attacher au fait d'être le filius de ses géniteurs). Le droit canonique médiéval saisit le réel en l'organisant dans un effort conjoint de dénomination et de taxinomie et impose de fait une figure implicite d'autorité, celle du ju-dex, qui " dit " le jus, le droit. La filiatio se dit donc (dicuntur) de quatre manières. Les fils "seulement légitimes" sont les " adoptés et les réclamés " (legitimi tantum, ut adoptivi aut arrogati), à côté des "légitimes et naturels " (legitimi et naturales), " naturels et non légitimes " (naturales et non legitimi), ou " bâtards " (proposition de traduction pour ce terme spurii qui renvoie aux individus " nés d'un adultère ou conçus vulgairement ", ut nati ex adulterio vel vulgo concepti ${ }^{17}$ ); ils "sont dits" (dicuntur) tels ${ }^{18}$. On retiendra l'importance de cette médiatisation du discours. On est " dit "

14. Decretales d. Gregorii papae IX [...] una cum glossis restitutae, Rome, 1582 (hébergées en ligne dans les Digital collections de l'UCLA).

15. Decretales..., op. cit., glose marginale. col. 1530.

16. McDougall, Sara, Royal Bastards. The Birth of Illegitimacy (800-1230), Oxford, Oxford University Press, 2017, chap. 1 " The Langage of Illegitimacy in Medieval Europe ", spécialement p. 22-49. Dans cette étude liminaire du " langage " et donc du vocabulaire de l'illégitimité dans la production médiévale, l'historienne du droit américaine met bien en évidence la complexité du lexique de la bâtardise : "The rather confusing variations in the meanings of various terms to evoke illegitimacy" (p. 23). Si le terme spurius est le plus utilisé dans la tradition juridique médiévale, civile ou canonique, il coexiste avec celui de mamzer, de tradition hébraïque, ou celui de nothus, de tradition grecque. Les variations dans les définitions que les uns et les autres mettent derrière ce terme nous interdisent d'en proposer une traduction figée. Le fait de naître d'une union illégale fait de vous un spurius dans le droit romain. Cette définition minimale sert de référence. Mais c'est seulement en replaçant le terme dans son contexte d'énonciation que nous pouvons comprendre s'il est question d'un adultère, d'un inceste ou d'un sacrilège.

17. La locution, volontairement dégradante, est fréquente pour dénoncer les conditions dans lesquelles l'enfant a été conçu : vulgairement, bassement (McDougaLl, Sara, Royal Bastards..., op. cit., p. 23).

18. Decretales..., op. cit., col. 1534-1535. 
(dicitur), on est " tenu " $\left(\right.$ habetur $\left.^{19}\right)$, on est " réputé " tel. Car c'est aussi une opportunité pour le sujet de se voir assigner des qualités nouvelles en proportion de ce que le droit prescrit. Deux catégories de fils ne voient pas leurs qualités infléchies par le droit : les fils qui jouissent de la faveur du mariage putatif de leurs parents et ceux qui pâtissent de l'illégalité et l'immoralité de l'adultère ou de l'inceste qui les a vus naître. Les premiers resteront "naturales et legitimi ", les seconds, "spurii ${ }^{20}$ ".

Le dispositif s'affine dans les décrétales postérieures d'Innocent III (11981216). Dans Ex tenore (c. 14), une veuve demande que son fils retrouve ses droits dans l'héritage de son mari, ce que la partie adverse conteste au motif que cette femme avait été épousée par un homme qui était en fait toujours marié; l'ignorance dans laquelle se trouvait la seconde épouse au moment où elle s'unit in facie ecclesie à son mari, et parce qu'elle " pensait " être une "épouse légitime " (dum ipsa conjunx ipsius legitima putaretur), autorise le pape à déclarer légitime la descendance de cette femme, in favorem prolis. Dans Gaudeamus (c. 15), la même "réputation " de légitimité est accordée à la progéniture d'un couple d'infidèles qui a procréé des enfants dans l'infidélité mais finit par se convertir, sans que leur conversion suffise à valider leur union conjugale car ils s'étaient mariés à un degré de parenté prohibé par la loi canonique ${ }^{21}$. Hereditas et successio sont donc déniées à l'illégitime, au contraire du légitime (ou du légitimé), né ou réputé tel. La réputation de légitimité permet de succéder au père, mais n'implique pas que ce père soit l'époux légitime de la mère. Or ce hiatus entre couple géniteur et couple conjugal pose la question des modalités de l'accueil de l'enfant, même bénéficiaire d'une identité juridique de légitime.

En droit canonique, si la légitimité vous rend éligible à l'héritage, le droit à être "nourri " ne procède pas de cette qualité juridique mais de la reconnaissance préalable (et indépendante) de votre filiation. Dans ce titre 17, seule la décrétale Cum inter d'Alexandre III donne matière à penser la manière dont se pose la question de la prise en charge de l'enfant, dans le cas où ses parents, sous le coup d'une sentence canonique de divortium, ne pourraient plus partager de communauté de vie : " Et pour cette raison, nous établissons que les fils qu'ils ont eus avant le divorce et qui ont été conçus avant que ne soit prononcée la sentence sont néanmoins tenus pour

19. Toute la réflexion canonique sur la possession de filiation rend compte des enjeux de cette médiatisation : la preuve de la possessio filiationis maternelle relève du témoignage des obstetrices; les preuves de possessio filiationis paternelle tiennent dans le fait d'" être tenu pour fils " (teneri pro filio) par ceux que le fils tiendra pour ses parents, et ce, publiquement attesté par la commune renommée (fama). Voir la glose de «testibus " (X., IV, 17, c. 4 Causam quae), qui renvoie d'ailleurs à la décrétale Per tuas. (Decretales..., op. cit., col. 1532). Voir Demoulin-AuZARY, Florence, Les actions d'état en droit romano-canonique : mariage et filiation (XIl -XVe siècles), Paris, 2004.

20. LEFEBVRE-TeILLARD, Anne, «Tanta est vis matrimonii : remarques sur la légitimation par mariage subséquent de l'enfant adultérin ", Autour de l'enfant..., op. cit., Leiden, Boston, 2008, p. 287-300.

21. Decretales..., op. cit., col. 1545-1546. 
légitimes et qu'ils succèdent aux biens paternels par droit héréditaire et qu'ils sont nourris en fonction des facultés des parents ${ }^{22}$. "Les réputés légitimes d'Ex tenore ou de Gaudeamus se retrouvent dans la même situation.

Les canons 3 et 4 du titre 17 (Transmissae nobis et Causam quae) développent un argumentaire qui pose les contours de la " possession de filiation ", possessio filiationis (les moyens de prouver une filiation contestée par les parents; les conséquences de cette preuve de possession d'état), et subséquemment ont permis à la doctrine de préciser les contours de l'obligation alimentaire ${ }^{23}$. Le cas dans Transmissae nobis est le suivant : un individu a "nourri un garçon jusqu'à son adolescence " (usque ad juventutem quendam puerum nutrisset), alors qu'il ne faisait que " cohabiter " avec celle qui est ensuite devenue son épouse mais qu'il n'avait pas encore épousée, - ce qu'il fit par la suite (postmodum); il eut d'elle ensuite des fils qui réclament finalement pour eux seuls l'héritage paternel. Le juvenis qui se comportait bien en fils et héritier (gerens se filium et haeredem) alors que dans le voisinage on le disait spurius, puisqu'on pensait qu'il était leur fils, conteste son exclusion de l'héritage. Mais $\mathrm{N}$. et son épouse avaient nié cette filiation, mettant sur le compte de l'" esprit de piété " (pietatis intuitu) le fait d'avoir «nourri " (nutrivisset) l'enfant. Comme le jeune homme ne s'est pas présenté à l'archevêque de Rouen sollicité pour résoudre le conflit, il est finalement excommunié; et le pape conclut qu'il faut s'en tenir aux paroles des époux, sauf si des preuves et des témoins permettent d'établir que le jeune homme était bien leur fils (nisi certis indiciis et testibus constiterit, esse filium juvenem memoratum). Retenons ici que "nourrir " un garçon plusieurs années jusqu'à ce qu'il entre dans l'âge de la " jeunesse " crée une présomption de filiation dans le voisinage. Par rapport au cas présenté dans la décrétale Cum inter, la cohabitation (concubinaire, en l'occurrence) de l'homme et de la femme évoqués simplifie toutefois la représentation qu'on peut se faire des modalités concrètes de cet entretien. La présomption de filiation qui s'y rattache procède de cette obligation qu'ont les parents de «nourrir » leurs fils, même illégitimes. Et c'est dans le titre 7 du livre IV de la compilation canonique qu'on trouve la formulation du principe juridique.

\section{"Qui fait l'enfant doit le nourrir " : retour aux sources ${ }^{24}$}

Ce titre 7 concerne le cas de « celui qui prend pour femme celle qu'il a préalablement souillée dans l'adultère " (de eo qui duxit in matrimonium

22. Ibidem, col. 1531 : Ideoque sancimus ut filii eorum, quos ante divortium habuerunt, et qui concepti fuerant ante latam sententiam, non mimus habeantur legitimi et quod in bona paterna haereditario jure succedant et de parentum facultatibus nutriantur.

23. Demoulin-Auzary, Florence, Les actions d'état en droit romano-canonique..., op. cit.

24. STEINBERG, Sylvie, Une tache au front..., op. cit., p. 146. Elle rappelle et contextualise cette " institution coutumière " que formule le juriste Antoine Loysel : "Quelques coutumes disent qu'un bâtard depuis qu'il est né est entendu hors de pain mais l'on juge que "qui fait l'enfant doit le nourrir". " (Antoine LoYSEL, Institutes coutumières, nouvelle édition par M. Dupin et E. Laboulay, Paris, 1846, 2 vol., livre I, XLI, 59, p. 91.) 
quam polluit per adulterium). La décrétale Cum haberet (X., IV, 7, 5) que promulgue Clément III évoque directement ce cas; que le couple incriminé ait engendré dix enfants ne constitue pas une circonstance atténuante et la règle canonique qui leur interdit le mariage après l'adultère s'applique sans nuance. La " multiplicité " de cette descendance aggrave plutôt le crime (cum multiplicitas prolis ita susceptae, magis eorum crimen exageret). Mais le pape concède qu'il " participera à [la] sollicitude [de l'évêque en charge de l'affaire] de faire en sorte que l'un et l'autre procurent le nécessaire à leurs enfants, en fonction de leurs facultés (sollicitudinis tamen tuae intererit ut uterque liberis suis, secundum quod eis suppetunt facultates, necessaria subministret) ${ }^{25}$ ". La glose ouvre alors deux dossiers d'autorités en commentant " intererit " et " secundum facultates " : " auprès de qui doivent demeurer les fils une fois le divorce prononcé (apud quem debeant demorari filii facto divorcio), et la règle relative à " l'administration des aliments " (hoc est regulare quod secundum facultates alimenta ministrentur)". Nous voici arrivés aux fondamentaux de ce que signifie " accueillir " en droit. La décrétale de Clément III précise que ce sont les deux parents (uterque, "l'un et l'autre ") qui doivent procurer le nécessaire aux enfants; et le pape emploie le terme " liberi ", qui désigne bien la position généalogique par rapport aux parents, sans considération d'âge, comme le ferait " filii ", terme générique qui dit le lien entre parents-géniteurs (parentes) et descendance (proles). Les âges de la vie sont toutefois réintroduits dans la glose pour dessiner les contours de cette obligation : " et note que le fils de moins de trois ans doit être nourri chez sa mère, et de plus de trois ans, chez son père (et nota quod filius minus triennio, ali debet apud matrem, major triennio apud patrem), conformément à ce qu'on lit dans le Code, De patria potestate, et supra, De conversione infidelium ${ }^{26}$ ". Le livre vill du code Justinien, au titre 47 (De patria potestate) présente en effet plusieurs développements fondamentaux sur le sujet des alimenta (dus par une fille à sa mère pauvre, en plus de la reverentia, comme le rappelle le civiliste du XIv ${ }^{\mathrm{e}}$ siècle Balde (mort en 1400), dans sa glose du c. 5 [Dioclétien et Maximien] mais aussi dus par le père du moment qu'il reconnaît le fils) ${ }^{27}$. Glosant le c. 9, Accurse (mort vers 1260) écrivait déjà bien : "agnoscere, id est tenere et alere ". La glose marginale précise en effet la référence que relaient les décrétalistes : «intra triennium ergo mater debet alere pater ab inde ${ }^{28}$ ".

Avant de préciser les contours de ce qu'alere signifie, revenons aux termes de la glose de l'Abbas siculus (Niccolo Tedeschi, dit Le Panormitain, mort en 1445) pour Cum haberet : après avoir détaillé les cas où le père

25. Decretales..., op. cit., col. 1482.

26. Ibidem.

27. Corpus juris civilis [...] commentariis Accursii, scholiis Contii, paratitlis Cujacii [...] novae accesserunt ad ipsum Accursium Dionysii Gothofredi, Lugduni, Sumptibus Horatius Cardon, 1604; consulté en ligne, hébergé dans la Harvard Law School Library; C. 8, tit. 47, c. 5 , col. 2000 .

28. Ibidem, col. 2002. La glose d'« intra triennium " renvoie encore à la lex alimentarum de la novelle 117 , c. 7. 
peut récuser l'obligation qui est la sienne d'alere filium, la glose rappelle que la mère doit être contrainte de nourrir ses fils (mater compellitur eos alere); si elle assume seule cette charge, alors que le père en avait aussi les moyens, elle peut exiger de lui des frais (si mater alit filium dum pater abundat, potest petere expensas). L'autorité du droit romain s'arrête à l'énoncé de ces principes qui, à lire la glose, ne bénéficieraient qu'aux légitimes (Sed haec quae dicta sunt intelleguntur de legitimis). Mais à la rigueur du droit civil (de rigore juris civilis), il faut opposer alors la « bienveillance canonique ${ }^{29}$ ". La bienveillance ou la bonté canonique invite à préférer le droit naturel au droit romain afin que soient " nourris ", " éduqués " ceux qui pourtant ne pourront pas succéder à leur père. Le propos était déjà exposé dans le commentaire proposé par le décrétaliste du XIII ${ }^{\mathrm{e}}$ siècle Hostiensis. Au livre IV, rubrique Qui filii sint legitimi, il organise sa pensée autour de l'idée d'une pluralité de genera de fils (" origines ", " extractions ", " genres "). La sixième question évoque le point de savoir si tous les fils, quelle que soit leur " origine ", leur " extraction ", doivent être " nourris " (An utrumque genus alatur) ${ }^{30}$ : selon les " lois " (sous-entendues civiles), ceux qui sont nés d'un inceste ne peuvent bénéficier de ce nourrissage (nati ex incestuso coitu nequaquam, secundum leges), mais :

" selon les canons, on agit avec plus de bonté (sed secundum canones agitur benignius) parce qu'ils veulent que ceux-ci soient nourris par l'un et l'autre parents selon leur faculté (quia volunt quod tales secundum facultates utriusque parentis alantur, ut supra de eo qui duxit in matrimonio quam poll[uit] per adulterium, Cum haberet, in fi[ne]) et c'est là la raison de la divergence entre droit civil et droit canon (ratio diversitatis) : parce que le droit civil puise son origine dans l'homme [...] tandis que le droit canon procède du droit naturel [...], aussi agit-il avec bonté (benignus agit). Il n'y a rien d'étonnant à ce que, au regard du droit naturel, les hommes nourrissent leurs fils (nec mirum, si vult, quod inspecto jure naturali homines filios suos alant), car même les animaux, en vertu de ce droit, enfantent des petits et les éduquent (nam et animalia ex hoc jure foetus pariunt et educant) [...] et bien davantage selon le droit canonique, lorsque presse la nécessité, il faut repaître celui qui meurt de faim (immo secundum jus canonum, instante necessitate, pasce fame morientem), parce que si vous ne l'aviez pas fait, vous l'auriez tué, et en vertu de ce principe, tous les fils doivent être nourris sans distinction (quodlibet genus ali debet) [...]. Les mineurs de trois ans relèvent de la prise en charge maternelle (solatio materno) plus que paternelle (quam paterno), comme on le voit supra, De conversione infidelium, dernier canon, à la fin, et de là vient qu'ils doivent être nourris par cette même mère (ideo ab ipsa matre ali debent). "

29. Decretales..., op. cit., glose Cum haberet, col. 1482-1483 : [...] de benignitate canonica que vigorem sumit a jure naturali : nam educatio filiorum de jure naturali est. I. dist. Jus naturale, et ex instinctu naturae, precedit : unde jus istud praefertur civili, tamen filii non succedent in bonis patris et illegitimi sunt.

30. Hostiensis, Summa aurea, Lyon, 1574 (hébergé en ligne par le Colby College), col. 1383. 


\section{Favor vs. sollicitudo, benignitas}

La lecture des textes canoniques évoquant la question des " aliments " permet, en contrepoint de l'analyse, de saisir ce que représente la favor prolis, précisément parce que c'est une notion que les décrétales, les gloses ou les commentaires du XIII ${ }^{\mathrm{e}}$ siècle qui en voit pourtant l'éclosion ne convoquent jamais pour justifier l'obligation alimentaire des parents à l'égard de leurs enfants.

L'idée selon laquelle il ne faudrait pas faire peser sur l'enfant le péché de ses parents est d'origine patristique mais s'impose tout spécialement sous la plume du canoniste de référence de l'épiscopat capétien Ives de Chartres (1040-1115) ${ }^{31}$. La menace de considérer comme illégitimes des enfants engendrés dans des configurations conjugales illicites ou douteuses semble davantage brandie quand les enfants ne sont pas déjà conçus et/ ou engendrés; en cela, l'évêque de Chartres paraît précurseur de l'idée même d'" intérêt de la descendance ${ }^{32}$ ". Il évoque également la possibilité de légitimer des enfants par le mariage réparateur de parents ni adultères, ni incestueux, en s'inspirant du droit romain ${ }^{33}$. L'expression favor prolis apparaît ensuite au XIII ${ }^{\mathrm{e}}$ siècle sous la plume d'Innocent III qui intègre dans le périmètre des héritiers du père les bénéficiaires du mariage putatif ${ }^{34}$. Dans sa summa aurea, c'est aussi à la question de savoir qui succède au père qu'Hostiensis oppose la favor au peccatum et odium parentum ${ }^{35}$. Au $\mathrm{XV}^{\mathrm{e}}$ siècle, Le Panormitain convoque aussi cette notion de favor filiationis dans sa glose de la décrétale Cum haberet (IV, 7, c. 5); ce n'est toutefois pas au chapitre des modalités de prise en charge des nombreux enfants nés du couple adultère évoqués dans le casus, mais pour introduire l'idée d'une dispense possible au mariage des adultères ${ }^{36}$. La contextualisation de l'idée puis de l'expression donne à voir combien ce principe relève du droit, dans son objet (permettre de succéder au père) et son sujet (la descendance,

31. McDougall, Sara, Royal Bastards..., op. cit., chap. 5 (Canon Law, Canonists, and Bastards in the World of Ivo of Chartres), p. 139-165, spécialement p. 145. Voir aussi LEFEBVRE-TeILlARD, Anne, “ À propos d'une lettre à Guillaume. La filiation légitime dans l'œuvre d'Ives de Chartres ", Autour de l'enfant..., op. cit., p. 239-258. Le droit à hériter est abordé dans le livre viII de son Décret consacré au mariage et au concubinage. Le canoniste prend également position sur ces sujets dans sa correspondance, au sujet du chevalier normand Guillaume ou des enfants de Philippe $\mathrm{I}^{\mathrm{er}}$ et de Bertrade de Montfort. C'est un dossier que nous avions également abordé, plus modestement que notre collègue américaine, dans Avignon, Carole, «Les stratégies matrimoniales des premiers Capétiens à l'épreuve des prohibitions canoniques en matière de parenté (XI ${ }^{-}$-XII ${ }^{\mathrm{e}}$ siècles) ", dans AuRELL, Martin (dir.), Les stratégies matrimoniales (IX ${ }^{e}$-XIII siècles), Turnhout, Brepols, 2013, p. 237-255, spécialement p. 247-254.

32. McDougall, Sara, Royal Bastards..., op. cit., note 31, p. 145.

33. Ibidem, note 32, p. 146.

34. X., IV, 17, c. 14 Ex tenore : « in favorem prolis potius declinamus, memoratum $R$. legitimum reputantes" (Decretales..., op. cit., col. 1546).

35. Hostiensis, Summa aurea..., op. cit., IV, Qui filii sint legitimi, 3. An utrumque genus succedat, col. 1380-1381.

36. X., IV, 7, c. 5 Cum haberet, glose « Multiplicitas" (Decretales..., op. cit., col. 1482). 
justement, en tant que telle, plus que l'enfant entendu comme âge de la vie). La sollicitudo (qu'invoque Clément III dans Cum haberet) ou la benignitas (mobilisée par la doctrine pour promouvoir le droit de nature plutôt que l'autorité des seules lois romaines afin d'assurer l'entretien de tous les enfants, quel que soit leur genus) ne fonctionne pas selon les mêmes logiques que l'argument de la favor prolis. La favor relève d'un champ autonome de la pensée canonique, quand elle aborde des questions relatives à la conjugalité et la sacramentalité du mariage ; c'est l'intérêt de la "lignée " (traduction possible de "proles ") qui est en jeu, et la capacité légale d'individus à pénétrer le cercle de la famille juridique. "Sollicitude " et " bonté " relèvent davantage des principes de l'amour dû au prochain, caritas chrétienne mais aussi pietas qu'évoquait le prétendu père de Transmissae nobis et qui rappelle une vertu de la culture romaine.

\section{Entretien et circulation des " nourris " : de la mère au père? Le témoignage des archives de la pratique}

Nous avons vu que c'est la doctrine canonique (et non directement le jus pontifical) qui a abordé la question des modalités de l'obligation alimentaire imposée aux parents, en déterminant qui y est éligible et au nom de quel principe, puis selon quels dispositifs concrets : auprès de qui (père ou mère?), jusqu'à quel âge, à la charge financière de qui. La doctrine canonique s'est en partie émancipée de l'héritage des romanistes pour élargir à toutes les catégories de fils ses obligations. Le seuil des trois ans, systématiquement avancé par les glossateurs et les commentateurs pour déterminer l'âge du passage de l'entretien par la mère à l'entretien par le père, dans une tradition civile clairement revendiquée, trouvait un écho dans le récit des mésaventures de sainte Marine dont nous avons parlé. Cela crée une catégorie d'âge particulière au sein de l'infantia qu'il conviendra de mettre en perspective avec les propositions des médecins et pédagogues du XIII ${ }^{\mathrm{e}}$ siècle, dont les plus lus sont Aldebrandin de Sienne (Régime du corps) et Barthélemi l'Anglais (De proprietatibus rebus, écrit au milieu du XIII ${ }^{\mathrm{e}}$ siècle et traduit en français par Jean Corbechon en 1372) ${ }^{37}$. Allaitement puis sevrage suffisent-ils à justifier ce choix? Cet âge, qui nous semble spécifique à la pensée juridique, ne recouvre ni celui de l'acquisition de la parole articulée et raisonnable (à 7 ans), ni la poussée dentaire (dientum plantatura) qui distingue physiologiquement une première infantia mais

37. Le régime du corps de maître Aldebrandin de Sienne. Texte français du XIII ${ }^{\mathrm{e}}$ siècle publié [...] d'après les manuscrits de la Bibliothèque nationale et de la Bibliothèque de l'Arsenal par les docteurs Louis Landouzy et Roger Pépin, Paris, 1911, p. 79 : « [...] si com li premiers quant il enfes est nés, et dure jusques à tant ke li dent commencent à venir : est infantia. L'autre, si est dentium plantatura, et c'est quand li dent sont venu et dure jusques à VII ans. La tierce est pueritia et dure jusques à XIIII ans "; Le livre des propriétés des choses. Une encyclopédie au XIVe siècle. Introduction, mise en français moderne et notes par Bernard Ribémont, Paris, 1999, livre VI, IV chapitre de l'enfant, p. 140-141 : " La petite enfance se termine à l'âge de sept ans, et là commence le second âge que nous appelons "enfance" en français et que l'on nomme pueritia en latin. " 
sans âge spécifique. Ce seuil dans l'enfance crée une spécification de genre dans les responsabilités alimentaires dans le cas (et seulement celui-ci) d'une filiation irrégulière. Passé l'âge de trois ans, l'enfant illégitime devrait être entretenu par le père; la glose du Panormitain ne donne pas à penser qu'il ne s'agirait que d'une prise en charge pécuniaire par le père. C'est bien " auprès de lui ", " chez lui ", apud, que l'enfant, à partir de 3 ans, doit être " nourri " (et sans doute jusqu'il soit devenu ce juvenis dont parlait le casus de Transmissae nobis ${ }^{38}$ ). Ce canoniste de la première moitié du $\mathrm{XV}^{\mathrm{e}}$ siècle traduit-il dans sa réflexion doctrinale ce que l'observation de la pratique lui confirmait par ailleurs, à savoir la fréquente circulation des enfants vers la domus d'un père qui s'épargne ainsi une forme de pension alimentaire?

Plusieurs travaux étayés par l'étude d'archives de la pratique confirment l'implication des pères (naturels) dans l'entretien des enfants (naturels) ${ }^{39}$. Lucie Laumonier rappelle dans sa thèse les remarques d'Anne Lester à propos des Coutumes du Beauvaisis commentées à la fin du XIII ${ }^{\mathrm{e}}$ siècle par Philippe de Beaumanoir : la fille-mère soupçonnée d'avoir abandonné le fruit d'une relation sexuelle coupable se défend de tout abandon en invoquant le don de l'enfant à son père ${ }^{40}$. Nous avons également rappelé les travaux de Marie-Thérèse Lorcin qui précisait que

38. X., IV, 7, c. 5, glose, Decretales..., op. cit, col. 1482.

39. Cet article n'a pas été le lieu de l'étude du sort réservé aux enfants naturels et/ou adultérins de la noblesse, ni des modalités d'accueil et d'entretien consenties par leur père naturel. La visibilité plus grande de ces bâtards nobles dans les lignages médiévaux, ainsi que leurs capacités à accéder au pouvoir dans le $\mathrm{XV}^{\mathrm{e}}$ siècle français sont bien connues depuis l'article fondateur de Mickaël Harsgor (HARSGOR, Mickaël, "L'essor des bâtards nobles au Xve siècle ", Revue Historique, 253, 1975, p. 319-354). Le colloque publié en 2015 sous la direction d'Eric Bousmar, Alain MARCHANDISSE, Christophe MASSON et Bertrand SCHNERB en faisait encore la démonstration, tout en soulignant la grande disparité de destins selon les carrières escomptées (armée, Église, robe), les niveaux de prestige et de puissance au sein d'une noblesse aux contours diversifiés mais aussi selon les territoires européens et les systèmes juridiques de référence qui s'y déploient ( $L a$ bâtardise et l'exercice du pouvoir en Europe du XIII au début du XVI siècle, Revue du Nord, Hors-série, collection Histoire $\left.n^{\circ} 31,2015\right)$. Le sort des bâtards royaux et leur place, quel que soit leur âge, dans la maison du père sont envisagés pour les IX ${ }^{\mathrm{e}}$-XIII ${ }^{\mathrm{e}}$ siècles par Sara Mc Dougall dans l'ouvrage déjà cité (Royal Bastards...). La question des sources est évidemment au cœur de toute délimitation d'un objet de recherche. Les archives urbaines, séculières, comme celles des tribunaux d'officialité n'ont pas vocation à surreprésenter la population nobiliaire. Or elles sont centrales dans nos corpus. Sans doute les registres de lettres de légitimation sont-ils une piste à privilégier pour poursuivre la réflexion sur l'accueil de l'enfant illégitime noble (et non pas seulement de manière générique du fils ou de la fille sans gradient d'âge). Depuis septembre 2016, Romain Chevalier prépare une thèse sur "Bâtardise et sociétés de cour au Xv e siècle ", à l'université d'Avignon, sous la direction de Guido Castelnuovo. Ce doctorat s'inscrit dans la continuité de ses recherches antérieures à partir des lettres de légitimation émises par la chancellerie de Charles VII (1430-1461) qui, sans être l'apanage des seuls nobles, les surreprésentent. Pour la période moderne, voir notamment STEINBERG, Sylvie, Une tache au front..., op. cit.

40. LAUMONIER, Lucie, Solitudes et solidarités en ville. Montpellier, mi XII⿸ -fin XVe siècles, Turnhout, Brepols, 2015, note 55, p. 117. LESTER, Anne, "Lost but not yet Found : Medieval Foundlings and their Care in Northern France, 1200-1500 ", Proceedings of the Western Society for French History, 35, 2007, p. 1-17. 
dans les testaments enregistrés devant la cour du Forez, ou à l'officialité de Lyon, un testament sur 17,6 évoque un "donné ${ }^{41}$ ". Nous avions également mis en perspective les remarques formulées par Philippe Maurice (à partir de la documentation notariée du Gévaudan du Xve siècle) quant à " la donation d'enfant [qui] sert à faire accueillir le bâtard dans la maison du père, tout en le faisant sortir de la celle de la mère ${ }^{42}$ " avec le témoignage de testaments bisontins au profit de "nourris " dont le statut de bâtards intégrés à la fratrie, dans la maison du père, ne faisait aucun doute $^{43}$. Bâtardise, nourrissage, donation fonctionnent bien souvent ensemble dans le concret des pratiques sociales ${ }^{44}$. L'illégitimité induit bien une forme de circulation des enfants qui rappelle certaines des caractéristiques du fosterage traditionnel tout en le dépassant puisque la translation de la mère au père n'implique pas seulement un entretien dans la maison du père le temps de la seule pueritia, mais souvent une donation/dévêture établie contractuellement ${ }^{45}$. On trouve confirmation que " nourrir " renvoie bien à des soins qui dépassent la seule alimentation : nutrire et alimentare ${ }^{46}$, élever et scolariser ${ }^{47}$, " élever, nourrir, vêtir ${ }^{48}$ ", accipere et nutrire [...] custodire ${ }^{49}$. On retrouve en écho le sens de l'expres-

41. LoRcin, Marie-Thérèse, Vivre et mourir en Lyonnais à la fin du Moyen Âge, Paris, CNRS, 1981.

42. Maurice, Philippe, La famille en Gévaudan au XVe siècle, Paris, Publications de la Sorbonne, 1998, p. 246-247. Voir aussi " Adoption et donation d'enfants en Gévaudan à la fin du Moyen Âge ", Droits et pratiques de l'adoption au Moyen Âge, Médiévales, 1998, vol. 17, $n^{\circ}$ 35, p. 83-92; «Actes de la pratique, II. L'adoption dans le Gévaudan (Xve siècle), p. 101-104.

43. Avignon, Carole, "Sans gens ni genus? ... ", art. cité, spécialement p. 141-145 ("Communauté familiale et parenté vécue : les mots pour le dire").

44. LAUMONIER, Lucie, "Bâtards et enfants naturels à Montpellier (XIV e-XVe siècles). De la caritas à la pleine paternité ", dans Avignon, Carole (dir.), Bâtards et bâtardises..., op. cit., p. 319-334, spécialement p. 328-334 (un acte d'abandon-donation d'un fils naturel par sa mère à son père est également proposé en annexe).

45. Voir les exemples de Philippe Maurice et de Lucie Laumonier, cités supra. Les actes notariés révélés prennent la forme d'actes charitables avec clauses de "vest " et de " dévest ", irrévocables à l'image des actes d'adoption étudiés par Roger Aubenas pour le Midi de la France. Voir par exemple comment un père putatif qui nie la paternité accepte l'entretien, ou en quels termes un père reconnaît ainsi le lien qui l'unit à l'enfant (G 1411/60v : ainsi Antoine Capdaviel "promisit et convenit nato puero ex utero dicte Johanne, ipsum puerum accipere et nutrire seu hoc fieri facere et custodire ut suum ", cité par MAURICE, Philippe, La famille..., op. cit., p. 247). Atypique semble le cas de noble Gabrielle Paulhan qui obtient une indemnité de son amant, le forgeron Guillaume Petit, mais décide de garder son fils et de le nourrir elle-même. Mais, précise l'acte, si elle le désire elle pourra le rendre et le transmettre à Guillaume qui sera tenu de « le recevoir, l'élever, de le nourrir, le vêtir ", cité par MAURICE, Philippe, La famille..., op. cit., p. 247 (3E 2899/190).

46. LAUMONIER, Lucie, "Bâtards et enfants naturels à Montpellier... ", art. cité, p. 329 (testament de Johan Cordier, 1451, pour que ses héritiers s'occupent de son fils naturel).

47. MAURICE, Philippe, La famille ..., op. cit., p. 246. Acte de donation d'un enfant par sa mère indigente à un prêtre pour qu'il l'accueille comme son frère et qu'il l'élève jusqu'à ce qu'il soit " à l'âge parfait " ; après quoi il le fera instruire dans une école (2665/168 vº et 2667/142). Sur l'aetas perfecta, voir METz, René, "L'enfant... ", art. cité, p. 14 : la notion en droit canon excède la simple infantia pour signifier l'âge requis pour le mariage ou l'entrée dans l'épiscopat...

48. Cité par MAurice, Philippe, La famille..., op. cit., p. 247 (3E 2899/190).

49. Ibidem, G 1411, fo $60 \mathrm{v}^{\mathrm{o}}$. 
sion de Cum haberet, à savoir necessaria subministrare. Mention est parfois faite du fils concerné par ces actes de donation comme d'un puer, mais sans autre indication sur son âge (plus ou moins de 3 ans?).

Dans les registres de procédure de l'officialité de Paris (1384-1387), Charles Donahue Jr n'a relevé qu'une seule action menée pour obtenir la prise en charge " alimentaire " d'un enfant naturel et sept cas où sont allégués des sponsalia de futuro carnali copula subsecuta, contenant des réclamations pour défloration et/ou paternité (sur 15) ${ }^{50}$. Ces archives parisiennes révèlent toutefois cinq dossiers instructifs ${ }^{51}$. Perrin Hangerii, clerc, est condamné à nourrir (ad nutriendum) à moitié (pro media parte) une fille prénommée Amelotte procréée il y a longtemps (diu) par lui avec Jeanne La Clergesse. Jean Episcopi est condamné à nourrir à moitié un petit enfant (infans!) (ad nutriendam pro media parte quemdam infantem nomine Guillemetam quam confessa fuit procreasse). Jean de Bresna est poursuivi pour avoir payé deux francs par an pendant six ans pour l'entretien de Béatrice (son alumpna) à Jean Riche. Est-ce sa " nourrie " au sens de bâtarde? Le tribunal le condamne à poursuivre l'entretien de celle-ci (pour la nourriture et le vêtement) maintenant que Jean Riche est incarcéré dans la prison de l'évêque de Paris. Charles Donahue rappelle que la cour prit la peine de siéger à Pâques pour régler cette question, témoignant ainsi de l'intérêt porté aux soins de ces alumni.

Les registres de sentences conservés pour l'officialité de Cambrai (14381453) révèlent aussi des pratiques qui rappellent certains principes canoniques relatifs à l'obligation alimentaire, et en tête, la responsabilisation du père ${ }^{52}$. Vingt-huit sentences prévoient que l'homme impliqué dans l'action judiciaire (en reconnaissance de fiançailles suivies de relations charnelles, dont il est finalement absous par le juge qui condamne parfois la partie demanderesse pour fausses allégations de conventions de mariage, ou pour conventions clandestines) contribue financièrement à l'entretien de la progéniture. Proles est le terme systématiquement employé (au singulier ou au pluriel); cela ne permet guère de savoir qui sont ces enfants (ni leur sexe, sauf rarissime qualification, ni leur âge au moment de l'action judiciaire). Il faut y ajouter quatre sentences qui condamnent l'homme à ce que nous appellerions aujourd'hui des dommages et intérêts pour la défloration de la mère sous la forme d'une " dotation ${ }^{53}$ " ainsi que les frais liés à l'accou-

50. Donahue, Charles, Jr., Law, Marriage and Society in the Later Middle Ages, Cambridge, 2007, p. 309 et 351. Une femme déflorée obtient de son amant qu'il « la dote, et la soutienne dans l'accouchement, et nourrisse pour moitié la fille procréée " (fuit condemnatus ad dotandum dictam filiam, et ad gubernandum ipsam in puerperio et [ad nutriendum] filiam per ipsum procreatum pro media parte); cas $\mathrm{n}^{\circ} 682$, cité dans l'annexe en ligne, p. 765.

51. Ibidem, chap. 7, note 253 ; en annexe $n^{\circ} 685$, p. 765 .

52. Registres de sentences de l'officialité de Cambrai (1438-1453), (éd.) Cyriel VleEschouwers, Monique VAn MELKEBEEK, Bruxelles, 1998, 2 tomes.

53. Registres de sentences de l'officialité de Cambrai..., op. cit., n ${ }^{\circ} 437$ (9 mars 1443), tome 1 p. 236 : [...] propter deflorationem predictam ad dotandum Robinetam [...] secundum ejus corree natalium dignitatem et ispius Jacobi bonorum facultatem. 
chement (expensa puerperii). Sur ces quatre sentences, deux révèlent que l'enfant mis au monde est décédé au moment de la promulgation de la sentence; on comprend alors qu'il n'est plus nécessaire de prévoir des " aliments ${ }^{54}$ ». Le 14 juillet 1444, l'official rend une sentence dans l'action engagée par promoteur contre Jean Perchon et Jeanne de Sars : les connaissances charnelles répétées sont avérées au point qu'il y a eu "procréation d'un enfant " (usque ad unius prolis procreationem), mais Jean est absous des allégations de promesses clandestines de mariage et n'est condamné qu'à l'acquittement des frais d'accouchement et aux dépens du procès ${ }^{55}$. Ici, ni " dotation " ni obligations alimentaires (sans qu'on nous spécifie si l'enfant a survécu ou non). Sur les vingt-huit premières sentences évoquées, deux ne spécifient pas expressément l'obligation alimentaire mais donnent à penser que la " dotation " serait versée par le père naturel parce qu'il y a eu défloration et naissance d'enfant ${ }^{56}$. Pour les autres, allusion est faite, en plus des frais d'accouchement, à une " prise en charge de la progéniture " (administratio prolium ${ }^{57}$ ) ou aux alimenta, aux nutrimenta ${ }^{58}$ ou à l'alimentatio ${ }^{59}$.

Quand le règlement de l'entretien de l'enfant est envisagé, les alimenta sont partagés entre père et mère, pro medietate, dans trois cas en 1438 et encore un en $1443^{60}$. L'allusion aux " facultés " des uns et des autres, à laquelle les papes n'avaient pas manqué de faire référence dès la seconde moitié du XII ${ }^{\mathrm{e}}$ siècle, n'est jamais évoquée pour autre chose que la " dotation " que l'homme doit à la femme ${ }^{61}$. La dos n'est envisagée par le juge

54. Ibidem, $\mathrm{n}^{\circ} 437$ (9 mars 1443), tome 1, p. 236; $\mathrm{n}^{\circ} 463$ (6 mai 1443), tome 1, p. 250.

55. Ibid., $\mathrm{n}^{\circ} 502$ (18 juillet 1444), tome 1, p. 278 : [...] in expensis per ream in puerperio predicto quam occasione processus coram nobis agitati factis.

56. Ibid., $\mathrm{n}^{\circ} 7$ (12 juillet 1438), tome 1, p. $8 ; \mathrm{n}^{\circ} 18$ (26 juillet 1438), tome 1, p. 13.

57. Ibid., $\mathrm{n}^{\circ} 3$ (5 juillet 1438), tome 1 p. 5 : Quia nobis constitit et constat pretactum reum eandem actricem deflorasse floreque sue virginitatis privasse, eapropter pretactum reum ad dotandum secundum suarum facultatum possibilitatem necnon secundum suorum natalium dignitatem necnon ad administrationem prolium ex eadem provenientium et in expensis legitimis ejusdem actricem.

58. Ibid., $\mathrm{n}^{\circ} 779$ (11 septembre 1445), tome 1, p. 449-450. Deux couples sont aux prises avec la justice de l'officialité : Beaudouin et Jeanne, engagés par des promesses clandestines suivies de relations charnelles, et ce même Beaudouin et Colette, qui ont également échangé des promesses de mariage suivies de relation charnelle, alors qu'ils savaient que Jeanne et lui étaient réputés s'être déjà engagés. Le juge reconnaît comme valide le second mariage, impose de le régulariser en le solennisant publiquement sous quarante jours mais enjoint tout de même à Baudouin de " doter Jeanne qu'il a déflorée, en fonction de la dignité de naissance de celle-là qui a été déflorée et la possibilité des facultés du défendeur, en même temps qu'aux dépens liés à l'accouchement, à la moitié des frais de nourrissage de l'enfant (nutrimentorum medie partis prolis) et de ce procès ". Précédemment dans la sentence, nous apprenions que l'enfant de Jeanne était un garçon (prolem una masculini sexus procreavit).

59. Ibid., no 914 (30 avril 1446), tome 1, p. 524; no 940 (15 juin 1446), p. 541.

60. Ibid., no $67,77,226$ et 422.

61. Ibid., $\mathrm{n}^{\circ} 3$, cité supra; $\mathrm{n}^{\circ} 7$, p. 8 : dans l'affaire qui oppose le promoteur et Marie Eggerix à Jean Rolants : [...] qui constitit atque constat predictum reum eandem denuntiatem deflorasse sepeque et sepius carnaliter cognovisse ac ex eadem unam prolem suscitasse, 
qu'en cas de perte de virginité de la femme engagée dans la procédure ${ }^{62}$. On constate aussi qu'aucune référence n'est faite non plus à l'âge des proles encore en vie au moment de la procédure. Ont-ils plus ou moins trois ans ${ }^{63}$ ? La prise en charge des expensa implique-t-elle l'hébergement de l'enfant dans la maison du père? Rien n'est jamais spécifié en ce sens (pour l'affirmer ou l'infirmer d'ailleurs). Quand on ne dit plus que père et mère assument à moitié les " aliments ", comme c'est le cas après 1438, cela signifie-t-il que le père est seul comptable de l'entretien de l'enfant? Rien ne nous est dit non plus sur la durée de cette obligation. La mention "ut jura volunt ", systématique à partir de février 1443, renvoie peut-être aux règles des "droits " (romain, canonique, coutumier) en matière d'obligation alimentaire et dispense peut-être l'official de les spécifier ${ }^{64}$. Les modalités d'exécution de la sentence restent ici (comme presque toujours) l'angle mort de la recherche sur la régulation judiciaire médiévale ${ }^{65}$.

Pour ce qui est du sort des enfants nés de prêtre ou d'adultère, notre information reste maigre. L'explication est sans doute à chercher dans le constat que promoteurs et officiaux ne semblent pas faire de la poursuite de la naissance illégitime en tant que telle une priorité (au mieux poursuivent-ils la fornication illicite, la faute donc plutôt que la conséquence de la faute) ${ }^{66}$. Rappelons que le rejet de ces spurii de la société chrétienne est même condamnée : ainsi Jeanne Noppée est-elle condamnée pour "fausse croyance " parce qu'elle aurait traité d'ung diaulot l'enfant d'un prêtre que tenait sa marraine sur les fonts baptismaux ${ }^{67}$. Quelques allusions témoignent de l'ambivalence de l'attitude des pères (putatifs) confrontés à

eapropter dictum reum ad dotandum secundum suarum facultatum possibilitatem et dictam denuntiantem secundum suorum natalium dignitatem. Ce sont les deux seuls cas où la dotation englobe dédommagement de la défloration et obligation alimentaire.

62. On relève qu'une sentence du 9 février 1443 ne fait pas référence à une " dotation " pour la mère (dont rien ne dit qu'elle a été déflorée); le juge prévoit seulement que le défendeur et père s'acquittera des "frais liés à l'accouchement et aux aliments de la descendance susdite " (dont le juge précisait supra que l'enfant procréé était " jusqu'ici toujours en vie ", [adhuc viventis]). Cela semble confirmer l'idée que la dot compense la défloration et cela seulement. Ibid., nº 422 (9 février 1443), tome 1, p. 225-226.

63. Dans quelques affaires, on comprend que l'enfant n'est pas encore né : ibid., $\mathrm{n}^{\circ} 556$ (21 octobre 1444).

64. Ibid., $\mathrm{n}^{\circ}$ 422. Les cinq seules exceptions dans les sentences promulguées par l'official Grégoire Nicolaï sont les sentences $\mathrm{n}^{\circ} 556,726,940$ et au tome 2, $\mathrm{n}^{\circ} 1255$ (pour un enfant à naître), 1312.

65. Sur les spécificités des sentences en matière matrimoniale, voir notamment AvIGNON, Carole, "Les mariages clandestins à l'épreuve d'un jugement en droit et en équité : le témoignage des sentences médiévales ", dans LEMESLE, Bruno, GARNOT, Benoît (dir.), Autour de la sentence judiciaire, Dijon, 2012, p. 171-179; LEFEBVRE-TEILLARD, Anne, Les officialités à la veille du concile de Trente, Paris, 1973.

66. Pour ce qui est de la situation à l'officialité de Troyes, voir McDougatl, Sara, "À la recherche des enfants illégitimes dans les archives de l'officialité de Troyes au $\mathrm{XV}^{\mathrm{e}}$ siècle. Un exemple atypique? ", dans Avignon, Carole (dir.), Bâtards et bâtardises..., op. cit., p. 207-210.

67. Registres de sentences de l'officialité de Cambrai..., op. cit., no 841 (4 décembre 1445), tome 1, p. 482-483. 
une naissance illégitime : pression pour pousser à l'abandon ou faire passer l'enfant pour celui d'un autre. Le 4 mars 1447, Jacques des Abliaux se voit imposer un serment purgatoire à cause d'une diffamation relative à une relation adultère avec une femme qui procréa un enfant (usque ad unius prolis procrationem) qu'il convainquit de l'abandonner à un autre (ipsam ut prolem hujusmodi vestituram alteri daret [...] instigasse et induxisse ${ }^{68}$. On relèvera l'emploi du terme de "vestitura " qui rappelle les actes de "vêt et de dévêt " trouvés dans la documentation notariale du Gévaudan. Le juge condamne Jacques à des " amendes " et une purgation canonique, dont on ne connaît malheureusement pas l'issue. Rien n'est dit d'une éventuelle responsabilisation pécuniaire comme père naturel de l'enfant adultérin allégué dans la procédure. Bien sûr, rien n'est dit non plus de sa survie ou non, ni même de la reconnaissance légale de cette paternité. Plus audacieuse encore est la stratégie révélée par la sentence du 5 juillet 1445 : Colard Nutus est un clerc marié qui a cherché à maquiller une naissance adultérine en poussant son propre fils légitime à épouser sa complice dans l'adultère (Margueritte Maruelle) et faire passer pour sien le fruit de ses amours coupables ${ }^{69}$. Marguerite met ainsi successivement au monde deux fils : celui de Colard et celui d'Éloi. Tous vivent sous le même toit. La question de l'entretien des deux enfants ne se pose donc pas; mais on devine sans peine que la sentence d'excommunication prononcée à l'encontre de Colard risque de modifier ce précaire équilibre, tout spécialement pour deux enfants qui s'imposent comme des spurii (un adultérin, un incestueux). Neuf sentences concernent ensuite des enfants naturels de prêtre. Aucune sentence n'évoque pour ceux-ci la mention d'aliments (même lorsqu'on nous précise que les enfants sont encore vivants au moment de la sentence) ${ }^{70}$. Jacques de Donckere, entre autres problèmes, est poursuivi pour avoir hébergé depuis des années une femme dont il avait eu " plusieurs enfants" (plures proles) : l'official constate la diffamation sur certains points de la procédure, et impose également le serment purgatoire, qui n'est pas une peine $^{71}$. Deux mois plus tard, il est absous des poursuites ${ }^{72}$. On le retrouve mentionné dans une sentence de mars 1445 comme victime d'une expédition punitive qui avait eu lieu en juin 1442 : le seigneur temporel de Pamel l'aurait notamment traité de "falsus paillardus ${ }^{73}$ ". Quid des enfants? Ceux-ci vivaient-ils aussi sous le même toit, comme ces enfants du curé de Maarke, Gérard Sackebant, poursuivi pour avoir vendu une rente sur les biens de son église paroissiale, sans autorisation préalable de l'évêque. L'affaire est jugée en 1446, mais les faits remontent à seize ans auparavant. L'official, Grégoire Nicolaï, constate que c'est sans doute pour veiller aux intérêts de sa concubine et de ses enfants (proles) qu'il avait aussi acheté des parcelles

68. Ibidem, $\mathrm{n}^{\circ} 1111$ (4 mars 1447), tome 2, p. 642.

69. Ibid., no 1175 (5 juillet 1449), tome 1, p. 682.

70. Ibid., no 464 (6 mai 1443), tome 1, p. 251-252.

71. Ibid., no 124 (24 janvier 1439), tome 1, p. 57-58.

72. Ibid., no 180 (21 mars 1439), tome 1, p. 86.

73. Ibid., n ${ }^{\circ} 659$ (6 mars 1445), tome 1, p. 374-375. 
qu'il labourait d'ailleurs chaque jour, " comme un laboureur ayant épouse et enfants légitimes" (ad modum censitorum et laboratorum conthorales ac proles legitimas habentium insistere pariter ac vacare consuevisse) ${ }^{74}$. En 1450, un autre prêtre concubinaire fait scandale en acceptant que " celle qui partage depuis quatre ans sa maison, sa table et son lit " (quandam eisdem domo, mensa, et lecto per quatuor annorum spatium in concubina ex qua plures suscitavit) aille tous les jours à la messe ${ }^{75}$. Sans doute ces enfants étaient-ils élevés dans cette maison où l'on dit que la concubine avait même accouché... Dans les cas où l'accueil du spurius est moins explicite, la justice n'intervient jamais pour signifier au prêtre concubinaire qu'il est redevable d'une obligation alimentaire. La benignitas canonica semble devoir céder le pas face au scandale d'un nicolaïsme persistant.

Dans les sociétés occidentales médiévales, il semble difficile de se défaire de cette vision canonique selon laquelle parere foetus implique de l'alere au point que les institutions charitables qui ont dû accueillir les enfants abandonnés (bâtards ou non) ont veillé autant que possible à connaître l'identité des pères pour leur imposer la prise en charge financière. Les différents termes convoqués pour signifier une prise en charge parentale s'organisent ainsi autour des expressions de nutrire (ou nutrimenta), alere (ou alimenta, alimentatio), necessaria subministrare, alimenta ministrere, parere et educare, educatio. Les différents acteurs (familiaux, institutionnels) de cet accueil de l'enfant se disent motivés par la "bonté ", la " bienveillance " (quand la paternité est reconnue) mais aussi la "charité " (quand la parenté est symboliquement convoquée, comme dans le cas des "fils du consulat " accueillis à Montpellier et étudiés par Lucie Laumonier ${ }^{76}$ ), ou la " piété " (quand, paradoxalement, la paternité n'est pas reconnue publiquement, comme dans le casus de Transmissae nobis). Mais il est souvent difficile de mesurer les modalités concrètes de ce " nourrissage " (ses acteurs, ses lieux, sa temporalité, son caractère impérieux au regard de la morale, de la loi, et donc son contrôle). Les sentences judiciaires étudiées révèlent toutefois combien le sort des spurii, les «bâtards " adultérins ou sacrilèges, reste précaire même quand la doctrine canonique a veillé à démontrer la nécessité d'assurer à tous les fils, quel que soit leur genus, ce que la nature exige du droit : des soins, comme Dieu avait accordé à Ismaël de l'eau pour survivre. Si le juge semble veiller avec des moyens finalement modestes à faire respecter les principes de l'obligation alimentaire, qu'est-ce qui permet d'en maintenir vivace la nécessité? Faut-il n'y voir que l'influence d'un droit romano-canonique dominant? Quelques pages de l'ouvrage de l'ethnologue Bernard Vernier intitulé Le visage et le nom proposent des clés d'analyse stimulantes pour

74. Ibid., $\mathrm{n}^{\circ} 640$ (6 février 1445), tome 1, p. 362-363.

75. Ibid., $\mathrm{n}^{\circ} 1318$ (20 juin 1450), tome 2, p. 761.

76. LAUMONIER, Lucie, "Bâtards et enfants naturels ... ", art. cité, p. 319-334. 
le médiéviste ${ }^{77}$. Il a étudié le système de parenté Karpathiote, à partir d'une population insulaire rurale grecque en mer Égée, et tout spécialement les règles de la nomination (qui conférait à celui qui doit hériter le nom de celui dont il hérite). Le premier-né des garçons porte le nom de son grand-père paternel (et le "ressuscite "); l'aînée des filles, celui de sa grand-mère maternelle. À cette règle de nomination des aînés de chaque sexe s'ajoute une théorie populaire des ressemblances familiales : le premier-né des garçons ressemble à sa mère (alors qu'il ressuscite son grand-père paternel), la première-née des filles ressemble à son père; le deuxième né de chaque sexe ressemble à son parent du même sexe. À partir du troisième né, l'ethnologue n'identifie plus de règle particulière : " ces cadets ressemblent un peu aux deux parents mais ne sont la réplique d'aucun. Ils sont "bâtards" (bastardemena) ${ }^{78}$ ". L'ethnologue conclut :

"Chez les Karpathos, les règles de nomination exercent un tel pouvoir de structuration sur les règles de la parenté que la famille est virtuellement menacée d'éclatement. La théorie des ressemblances semble avoir pour fonction de contrecarrer les effets dysfonctionnels de l'attribution de chacun des enfants et surtout des aînés à un parent déterminé, ou pour le dire autrement, de créer les conditions d'une bonne collaboration entre les parents. [...] La théorie des ressemblances rattache chaque aîné à celui des deux parents qui, d'une autre lignée que lui, pourrait être tenté de le négliger ${ }^{79}$."

Cette théorie rappelle ce que Bronisław K. Malinowski avait identifié chez les Trobriandais. Comme le résume Bernard Vernier, dans ce système matrilinéaire, les parents maternels « sont considérés comme faisant partie du " même corps ", tandis que le père est considéré comme un "étranger " ${ }^{80}$. Et pourtant, il est convenable de donner à entendre qu'un enfant ressemble à son père. Malinowski donne deux éléments d'explication de ce qui pourrait apparaître comme un paradoxe, et expose cette " doctrine sociale relative à l'influence du père sur le physique de l'enfant " :

"Un de ceux-ci m'a expliqué la chose [...] en tournant vers moi ces mains ouvertes, les paumes dirigées vers le haut : "Mettez là-dessus une matière molle, elle prendra tout de suite la forme de la main. De même le mari reste avec la femme et façonne l'enfant." Un autre m'a dit : "C'est de notre main que l'enfant reçoit la nourriture, c'est nous qui lui donnons fruits et gourmandises, c'est nous qui lui donnons des noix de bétel. C'est grâce à celui qui le nourrit l'enfant devient ce qu'il est ${ }^{81}$." "

De ces réflexions d'ethnologues, retenons certains effets de parallélisme (à défaut de continuité) dans la mobilisation de la qualification de « bâtard ", tout en paradoxe, pour désigner celui qui n'est à personne (puisqu'il ne ressemble à aucun des deux parents, dans les représentations karpathiotes),

77. VERNIER, Bernard, Le visage et le nom. Contribution à l'étude des systèmes de parenté, Paris, PUF, 1999.

78. Ibidem, p. 14-15.

79. Ibid., p. 20.

80. Ibid., p. 15.

81. Ibid., p. 17. 
et peut bien ressembler un peu aux deux parents. Les représentations occidentales ont beaucoup joué sur les métaphores de l'hybridation pour parler des bâtards ${ }^{82}$, tandis que la doctrine canonique a pu de son côté élaborer aussi une théorie du spurius qui n'aurait de consanguins qu'en ligne maternelle et serait donc, en droit, celui qui ne partage son sang qu'avec l'un de ses géniteurs, sa mère en l'occurrence ${ }^{83}$. L'idée s'impose qu'on peut $n$ 'être à personne, ou du moins ne pas appartenir à son père (puisqu'on n'héritera pas de lui ${ }^{84}$ ), symboliquement ne pas être de son sang, et devoir être nourri par lui. Et c'est ce "nourrissage " qui crée le lien. Dans les systèmes traditionnels, comme dans la pensée romano-canonique occidentale, l'altérité se fonde sur des critères extérieurs à l'enfant lui-même, sa position dans la fratrie ou la qualité juridique du couple parental, en fonction de son éligibilité au sacrement de mariage. Cette altérité crée finalement un dysfonctionnement qu'il faut, ou qu'il aura fallu, compenser symboliquement par la disjonction de ce qu'impose le droit et de ce que requiert la nature.

82. Ainsi « mulet " ou " bardot ", pour désigner les bâtards des princes piémontais comme le rappelle GENTILE, Luisa Clotilde, "Les bâtards princiers piémontais et savoyards ", dans Bousmar, Éric, MARCHANDISSE, Alain, MASSON, Christophe, Schnerb, Bertrand (dir.), La bâtardise et l'exercice du pouvoir en Europe du XIII au début du XVI siècle, Revue du Nord, horssérie, Collection Histoire, n 31, 2015, p. 387-410, ici p. 387. GîRBÉA, Catalina, "Filiations diaboliques dans le roman médiéval du XIII ${ }^{\mathrm{e}}$ siècle ", dans Avignon, Carole (dir.), Bâtards et bâtardises..., op. cit., p. 477-488.

83. HostiEnsis, Summa aurea (livre IV, titre 14, de consanguinitate et affinitate). La consanguinitas est un lien (vinculum) et le groupe des personnes unies, attachées les unes aux autres (attinentia unius personnae ad alteram) par ce lien, en ligne descendante et ascendante à partir d'une souche (stirps) ou d'une origine (origo) commune. Le " lien " est créé par "propagation charnelle" (carnali propagatione). Ce terme permet, poursuit-il, "pour ainsi dire " (quasi), de désigner l'ensemble de " ceux qui possèdent un sang commun ", quasi communem habentes sanguinem. Or, au titre 17, il explique que le bâtard n'est intégré qu'à la consanguinité cognatique.

84. C'est bien le sens en droit romain, repris par la doctrine canonique de ne pas relever de sa " patria potestas", de ne pas être " filius familias ". Voir la glose martienne de la Summa aurea d'Hostiensis (Quum filii legitimi a parentibus ali debeant), op. cit., col. 1383. THomas, Yan, "L'enfant à naître et "l'héritier sien”. Sujet de pouvoir et sujet de vie en droit romain ", Annales HSS, 62-1, 2007, p. 29-68. 


\section{RÉSUMÉ}

Cette communication se propose de mobiliser dans leur diversité les représentations de l'enfant bâtard à travers plusieurs corpus documentaires médiévaux, de son rejet et sa stigmatisation aux modalités symboliques, affectives, juridiques ou judiciaires de son accueil, ainsi que les premières significations anthropologiques qu'il est possible de commencer à dégager de ces différents dossiers. Les réflexions sur la filiation sont polarisées en droit romano-canonique médiéval par la question de savoir qui " succède " en ligne paternelle (en l'occurrence, seuls les légitimes et les légitimés) et qui doit être " nourri ". Le droit canonique divergerait alors de la pensée des romanistes qui ont pourtant permis de définir les contours de l'obligation alimentaire et les cadres de la responsabilisation des pères naturels (à partir des trois ans de l'enfant) : à compter de la seconde moitié du XII ${ }^{\mathrm{e}}$ siècle, s'affirme progressivement le principe que même illégitimes, spurii inclus, les enfants doivent être " nourris " par leurs parents. En marge d'une réflexion sur la favor prolis, papes et décrétalistes soutiennent le principe de l'accueil et de la prise en charge des illégitimes par leurs parents, et notamment par leur père auquel ils ne sauraient toutefois jamais succéder. La sollicitudo et la benignitas enjoignent de faire triompher le jus naturale sur les éventuelles restrictions du droit positif. Le témoignage des archives de la pratique (actes notariés, testaments, archives judiciaires d'officialités) invite toutefois à nuancer ces postures bienveillantes, tout en confirmant la réalité de la responsabilisation des pères naturels, de facto comme de jure.

\section{ABSTRACT}

This paper examines the representation of children considered as bastards in medieval sources, both as rejected and stigmatised figures because they were born outside of wedlock and as children that society and parents had to take care of, who were symbolically, legally and judicially protected. They could not inherit of their father, at least in theory, but they had to be fed and educated, or had to contribute by alimenta to do it. Canonists diverged from romanists who nevertheless defined what nutrire or alere meant because from the second part of the twelfth century, popes and decretalists, step by step, demonstrated that parents had to take care of their children, even those who had been born spurii. The idea that supported this form of representation of bastards had nothing to do with favor prolis but simply sollicitudo or benignitas canonica that obliged everyone to put at the first rank the jus naturale instead of human laws that might have restricted bastard's rights. But those canonical demonstrations had to be precisely qualified by notarial or judicial sources that proved the father's obligations but also difficulties for spurii. Those medieval representations, sometimes paradoxical, are also compared with conclusions taken from anthropological studies. 